\title{
Sunitinib combined with pemetrexed and carboplatin in patients with advanced solid malignancies—results of a phase I dose-escalation study
}

\author{
Normand Blais • D. Ross Camidge • Derek J. Jonker • Denis Soulières • \\ Scott A. Laurie - Sami G. Diab - Ana Ruiz-Garcia • Aron Thall • \\ Ke Zhang • Richard C. Chao • Laura Q. Chow
}

Received: 1 August 2013 / Accepted: 2 August 2013 / Published online: 22 August 2013

(C) The Author(s) 2013. This article is published with open access at Springerlink.com

Summary Objectives The maximum tolerated dose (MTD) and overall safety of sunitinib plus pemetrexed and carboplatin was determined in patients with advanced solid malignancies. Methods In this phase I dose-escalation study, patients received oral sunitinib on a continuous daily dosing (CDD) schedule (37.5 mg/day) or Schedule 2/1 (2 weeks on treatment, 1 week off treatment; 37.5 or $50 \mathrm{mg} /$ day). Pemetrexed (400-500 mg/ $\mathrm{m}^{2} \mathrm{IV}$ ) and carboplatin (AUC $=5 \mathrm{mg} \cdot \mathrm{min} / \mathrm{ml} \mathrm{IV}$ ) were administered $\mathrm{q} 3 \mathrm{w}$. At the MTD for the chosen schedule, a cohort of patients with non-small cell lung cancer (NSCLC) or mesothelioma was further evaluated. Results Twenty-one patients were enrolled on Schedule 2/1 (expansion cohort included) and 3 patients on the CDD schedule. The MTD on Schedule 2/1 was sunitinib $37.5 \mathrm{mg} /$ day with pemetrexed $500 \mathrm{mg} / \mathrm{m}^{2}$ and carboplatin $\mathrm{AUC}=5 \mathrm{mg} \cdot \mathrm{min} / \mathrm{ml}$; MTD on the CDD schedule was not established. Dose-limiting toxicities included grade 3/4 neutropenia, grade 3 thrombocytopenia, and grade 3 hand-foot syndrome. The most common grade $3 / 4$ drug-related non-

N. Blais $(\bowtie) \cdot D$. Soulières

Centre de Lutte Contre le Cancer du CHUM - Hôpital Notre-Dame, 6ième étage (G6162), Pavillon Deschamps, 1560 Sherbrooke Est,

Montréal, QC H2L 4M1, Canada

e-mail: normand.blais@geoq.com

D. R. Camidge

University of Colorado Cancer Center, Aurora, CO, USA

D. J. Jonker $\cdot$ S. A. Laurie $\cdot$ L. Q. Chow

The Ottawa Hospital Cancer Centre, Ottawa, Canada

S. G. Diab

Colorado Integrative Cancer Center, Aurora, CO, USA

A. Ruiz-Garcia $\cdot$ A. Thall $\cdot$ K. Zhang $\cdot$ R. C. Chao

Pfizer Oncology, La Jolla, CA, USA hematologic adverse events at Schedule 2/1 MTD were fatigue/asthenia and diarrhea (both $n=4$ ). Grade 3/4 hematologic abnormalities included neutropenia (83\%) and leukopenia $(83 \%)$. Pharmacokinetic data revealed no clinically significant drug-drug interactions. Best response at the Schedule 2/1 MTD was stable disease $\geq 8$ weeks in $3 / 5$ evaluable patients (60\%). Conclusions With this combination, in patients with advanced solid malignancies, sunitinib MTD on Schedule 2/1 was $37.5 \mathrm{mg} /$ day. Sunitinib plus pemetrexed and carboplatin were tolerable at the MTD, although sunitinib dose delays and reductions were often required due to myelosuppression.

Keywords Solid tumors · Non-small cell lung cancer · Sunitinib $\cdot$ Pemetrexed $\cdot$ Carboplatin

\section{Introduction}

Sunitinib is an oral, multitargeted tyrosine kinase inhibitor of vascular endothelial growth factor receptors (VEGFRs 1-3) and platelet-derived growth factor receptors (PDGFRs $\alpha$ and $\beta)$, as well as other receptors [1-6]. VEGF and PDGF are key angiogenic ligands that influence cancer growth, progression, and metastasis [7-10]. Sunitinib is approved multinationally for the treatment of advanced renal cell carcinoma (RCC) and imatinib-resistant or -intolerant gastrointestinal stromal tumors (GISTs) [11]. In a phase II trial, single-agent sunitinib was well tolerated and associated with an encouraging response rate $(11.1 \%)$ in patients with previously treated advanced non-small cell lung cancer (NSCLC) [12, 13] and has also shown antitumor activity in patients with other solid malignancies, such as pancreatic neuroendocrine tumor, sarcoma, thyroid cancer, and melanoma [14, 15]. Both 
intermittent and continuous daily dosing (CDD) schedules of sunitinib have shown similar efficacy and tolerability in patients with RCC, GIST, and NSCLC. The approved dose for RCC and GIST is $50 \mathrm{mg} /$ day administered in 6-week cycles comprising 4 weeks on treatment followed by 2 weeks off treatment (Schedule 4/2), and the approved dose for pancreatic NET is $37.5 \mathrm{mg} /$ day CDD [12, 13, 16-19].

Pemetrexed is a chemotherapeutic agent that targets multiple folate pathway enzymes resulting in inhibition of cellular replication. It has clinical activity in a range of solid tumors [20]. While single-agent pemetrexed is approved for secondline or maintenance treatment of patients with non-squamous advanced NSCLC, response rates in the second-line setting remain low $(<10 \%)$ and there is a need for treatment combinations with improved efficacy $[21,22]$. Pemetrexed in combination with carboplatin is active in multiple tumor types including NSCLC, small-cell lung cancer, and mesothelioma, and has different toxicities than pemetrexed with cisplatin [23-25].

The addition of antiangiogenic agents to chemotherapy has shown additive or synergistic effects in preclinical models [26-28]. Changes in tumor vasculature initiated by antiangiogenic agents appear to enhance chemotherapy diffusion and delivery, possibly by reducing interstitial pressure and increasing permeability and perfusion [7, 29]. Sunitinib combined with pemetrexed decreased tumor growth in NSCLC NCI-H460 xenograft models [26], although a recent phase II study in patients with advanced NSCLC did not show a benefit for the combination over pemetrexed alone as second-line therapy [30]. Clinical evidence from other antiangiogenic agents, such as the anti-VEGF monoclonal antibody bevacizumab, further support the benefit of combination therapy versus chemotherapy alone in patients with solid tumors including advanced non-squamous NSCLC [31, 32] and colorectal cancer [33].

The primary objective of this phase I dose-escalation study was to determine the maximum tolerated dose (MTD) and overall safety of sunitinib (on intermittent and CDD schedules) in combination with pemetrexed and carboplatin in patients with advanced solid malignancies.

\section{Methods}

\section{Study population}

Patients aged 18 years or older with Eastern Cooperative Oncology Group (ECOG) performance status of 0 or 1 were enrolled. Patients had a histologic or cytopathologic diagnosis of solid malignancy refractory to standard therapy or for which no standard therapy existed, adequate organ function (including bone marrow, kidney, and liver), and a life expectancy of $\geq 12$ weeks. In the expansion cohort, previously treated and/or platinum- refractory/-intolerant patients with recurrent or advanced NSCLC of any histologic subtype and patients with advanced unresectable mesothelioma (pleural or peritoneal; stage 3 or 4) were eligible for enrollment.

Patients were excluded if they had uncontrolled or symptomatic brain metastases; gross hemoptysis $(\geq 5 \mathrm{ml}$ per episode or $\geq 10 \mathrm{ml}$ per day) within 4 weeks of study start; uncontrolled hypertension $(>150 / 100 \mathrm{mmHg}$ ) despite standard antihypertensive agents; or cardiac disease, cerebrovascular accident or pulmonary embolism within 12 months of starting the study. Other exclusion criteria included: National Cancer Institute (NCI) Common Terminology Criteria for Adverse Events (CTCAE) grade 3 hemorrhage within 4 weeks of treatment; ongoing cardiac dysrhythmias of grade $\geq 2$; atrial fibrillation of any grade; prolongation of the QTc interval ( $>450 \mathrm{~ms}$ for males or $>470 \mathrm{~ms}$ for females); chemotherapy, surgery or radiation therapy less than 4 weeks before study start (except palliative radiotherapy to non-target lesions); known hypersensitivity to carboplatin; or prior treatment with pemetrexed, carboplatin, or sunitinib.

\section{Study design and treatment}

This open-label, multicenter, phase I trial (NCT00528619) conducted in the US and Canada investigated escalating doses of sunitinib plus pemetrexed and carboplatin in combination in serial patient cohorts. The primary objective was determination of the MTD and overall safety of sunitinib administered in combination with pemetrexed and carboplatin in patients with advanced solid malignancies for which curative therapy was not available. Secondary endpoints included pharmacokinetic (PK) parameters and the preliminary antitumor activity of this combination.

Sunitinib (37.5 or $50 \mathrm{mg}$ ) was administered orally once daily on either the CDD schedule or Schedule 2/1 (2 weeks on treatment followed by 1 week off treatment). Pemetrexed $\left(400-500 \mathrm{mg} / \mathrm{m}^{2} \mathrm{IV}\right)$ and carboplatin $(\mathrm{AUC}=5 \mathrm{mg} \cdot \mathrm{min} / \mathrm{ml}$ IV) were administered once every 3 weeks (q3w). Planned dose escalation cohorts (Table 1) followed a standard $3+3$ design and began with the CDD schedule. The dose levels were based on the previous MTD determinations for sunitinib in combination with pemetrexed (i.e., sunitinib $37.5 \mathrm{mg}$ /day on the CDD schedule and $50 \mathrm{mg}$ /day on Schedule 2/1; pemetrexed $500 \mathrm{mg} / \mathrm{m}^{2}$ ) [34].

Treatment cycles lasted 3 weeks, and patients received up to six cycles of triple combination treatment. Upon study completion, patients who continued to experience clinical benefit were eligible to enter a continuation study to receive sunitinib either alone or together with any or all components of the original treatment combination, at the investigator's discretion. Patients with RECIST-defined progressive disease but who were judged as benefiting from treatment were also eligible to enroll into the continuation protocol. 
The MTD was defined as the highest dose at which $0 / 3$ or $\leq 1 / 6$ patients experienced a dose-limiting toxicity (DLT) during the first 22 days of treatment, with the next higher dose level having at least $2 / 3$ or $2 / 6$ patients with a DLT. DLTs were defined as grade 3 or 4 drug-related toxicities that occurred during the defined time frame or that resulted in a delay in administering cycle 2 . Hematologic DLTs were defined as neutropenia (grade $\geq 3$ with grade $\geq 3$ infection; grade 4 lasting $\geq 7$ days or with fever $>38.5^{\circ} \mathrm{C}$ lasting $>24 \mathrm{~h}$ ), thrombocytopenia (grade $\geq 3$ with bleeding or grade 4 for $\geq 7$ days), or lymphopenia accompanied by an opportunistic infection. Nonhematologic DLTs included grade 3/4 toxicities lasting $\geq 7$ days. Nausea, vomiting, and diarrhea that persisted at grade $3 / 4$ despite maximal medical therapy were also considered DLTs.

Depending on the safety profiles of the CDD schedule and Schedule 2/1, one dosing schedule could be further explored in a separate cohort of up to an additional 10 patients with NSCLC and up to 10 patients with mesothelioma (the expansion cohort) treated at the MTD.

All patients provided written informed consent. The study was approved by the institutional review board of each participating center and was carried out in accordance with the International Conference on Harmonization Good Clinical Practice guidelines, and applicable local laws and regulatory requirements.

\section{Study assessments}

Safety was evaluated at each patient visit by the assessment of adverse events (AEs; NCI CTCAE version 3.0), laboratory abnormalities, physical examinations, and vital signs. Electrocardiogram profiles were obtained at baseline and cycle 1 . The AEs related to each study drug were evaluated to determine the safety of the triple combination.

Full PK profiles for sunitinib, SU12662 (its primary active metabolite), the sum of sunitinib plus SU12662, pemetrexed, and carboplatin (as total and free [unbound] platinum) were obtained from the last 3 patients enrolled in the Schedule 2/1 MTD cohort. Pemetrexed and carboplatin PK samples were collected on cycle 1 day 1 (i.e., in the absence of sunitinib) and cycle 2 day 1 (in the presence of sunitinib). Sunitinib PK samples were collected on cycle 2 day 1 . To obtain steadystate values, only patients who received at least 10 consecutive doses of sunitinib prior to sample collection on cycle 2 day 1 were included in the summary. Similarly, for the sunitinib PK data used as reference (historical control, NSCLC patients receiving sunitinib as single therapy) only patients who received at least 10 consecutive doses of sunitinib prior to sample collection were included. Pharmacokinetic parameters were estimated using non-compartmental methods, and included $\mathrm{C}_{\max }$ (maximum plasma concentration), $\mathrm{T}_{\max }$ (time to $\mathrm{C}_{\text {max }}$ ), $\mathrm{AUC}_{24}$ (area under the plasma concentration-time curve from time zero to $24 \mathrm{~h}$ ), $\mathrm{AUC}_{\infty}$ (AUC from time zero to infinity), $\mathrm{CL}$ (clearance), and $t_{1 / 2}$ (terminal phase half-life).

Computed tomography (CT) or magnetic resonance imaging (MRI) scans were performed at screening, at every evennumbered cycle, whenever disease progression was suspected or to confirm a response, and at the end of treatment/ withdrawal from the study. Brain CT or MRI and/or bone scan were performed as clinically indicated. In patients with measurable disease, objective response was determined according to Response Evaluation Criteria in Solid Tumors (RECIST version 1.0) [35].

\section{Statistical methods}

Due to the exploratory nature of this study, no confirmatory inferential statistical analyses were planned. Descriptive statistics were used to summarize all patient characteristics, treatment administration/compliance, safety, PK parameters, and antitumor activity.

\section{Results}

Patient characteristics

Three patients were enrolled into the CDD and 15 into the Schedule 2/1 dose-escalation cohorts (Table 1). An additional 6 patients with NSCLC $(n=5)$ and mesothelioma $(n=1)$ were subsequently enrolled into the expansion cohort on Schedule $2 / 1$ (see below). In the expansion cohort, all 6 patients had undergone previous surgery and 4 had undergone prior radiation therapy. One had received prior systemic treatment (1 regimen). The median duration since first diagnosis was 1.7 months (range, 0.3-5.0) for the patients with NSCLC and 3.5 months for the patient with mesothelioma. In total, these 24 patients received 98 cycles of sunitinib therapy, 99 cycles of pemetrexed therapy, and 99 cycles of carboplatin therapy (Table 1). Patient demographic and baseline characteristics are summarized in Table 2.

Safety

\section{Schedule 2/1}

The MTD on Schedule 2/1 was determined to be sunitinib $37.5 \mathrm{mg} /$ day + pemetrexed $500 \mathrm{mg} / \mathrm{m}^{2}+$ carboplatin $\mathrm{AUC}=5$ $\mathrm{mg} \cdot \mathrm{min} / \mathrm{ml}$. At the Schedule 2/1 MTD, one DLT of grade 3 neutropenia was observed (Table 3). In the escalation cohort above this dose (sunitinib $50 \mathrm{mg} /$ day + pemetrexed $500 \mathrm{mg} / \mathrm{m}^{2}+$ carboplatin $\mathrm{AUC}=5 \mathrm{mg} \cdot \mathrm{min} / \mathrm{ml}$ ), DLTs of grade 3 thrombocytopenia $(n=1)$ and grade 4 neutropenia $(n=2)$ were observed (Table 3). 


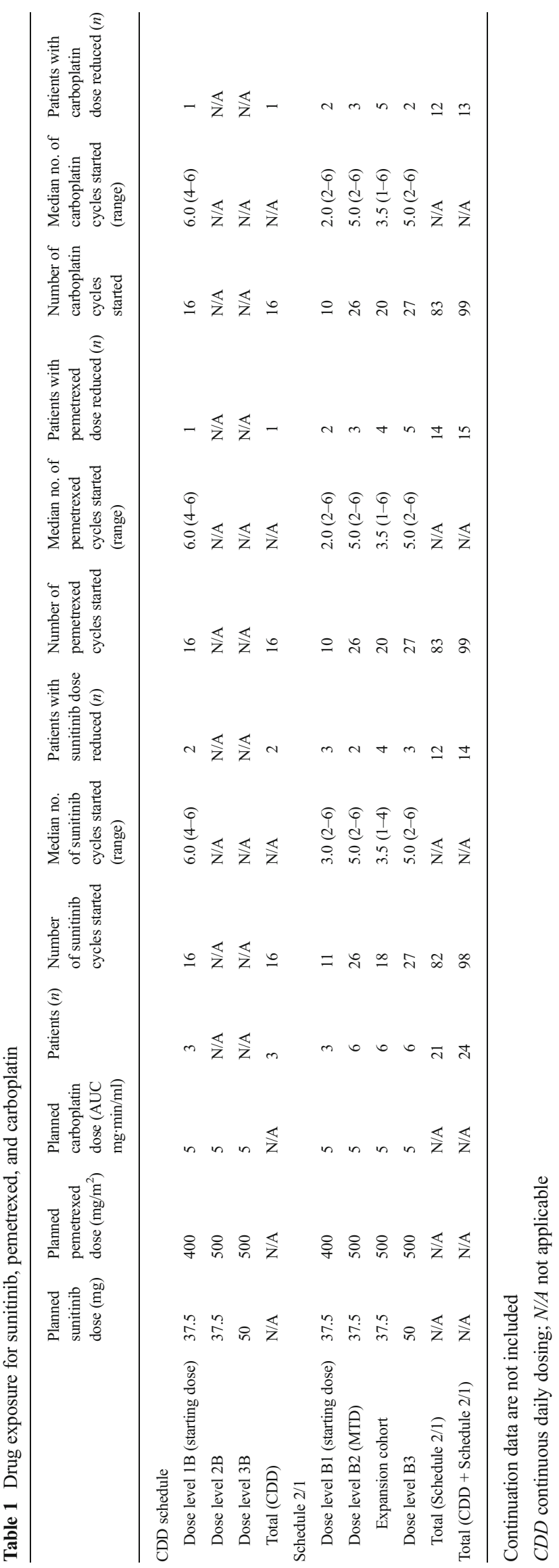

In total, $9 / 12$ patients $(75 \%)$ treated at the Schedule $2 / 1$ MTD had at least one sunitinib dose delay, with 1 patient (8\%) having a delay of 3-4 weeks. Additionally, 6 patients $(50 \%)$ in this cohort had a sunitinib dose reduction to $25 \mathrm{mg}$. Six patients discontinued sunitinib at the MTD due to AEs (neutropenia $[n=3]$, fatigue, diarrhea, and clostridial infection [all $n=1]$ ). The diarrhea was considered by the investigator to be related to sunitinib and pemetrexed, while the neutropenia and fatigue were attributed to all three study treatments. The median number of cycles of sunitinib, pemetrexed, and carboplatin received per patient was 5.0 (range 2-6) in the original Schedule 2/1 MTD cohort $(n=6)$, and 3.5 (range 1-4) in the expansion cohort ( $n=6$; Table 1$)$. The dose of sunitinib was reduced to $25 \mathrm{mg}$ in 2 patients $(33 \%)$ in the original Schedule 2/1 MTD cohort and 4 patients $(67 \%)$ in the expansion cohort (Table 1). Of these 6 patients, four discontinued sunitinib within 12 weeks after dose reduction, while the other two continued for 13-24 weeks. The dose of pemetrexed was reduced to $400 \mathrm{mg} / \mathrm{m}^{2}$ in 3 patients $(50 \%)$ in the Schedule 2/1 MTD cohort and 4 patients $(67 \%)$ in the expansion cohort. All but one discontinued pemetrexed within 12 weeks after dose reduction. The dose of carboplatin was reduced up to $30 \%$ in 3 patients $(50 \%)$ in the Schedule $2 / 1$ MTD cohort and 5 patients ( $83 \%$ ) in the expansion cohort. Of these 8 patients, four discontinued carboplatin within 12 weeks after dose reduction, and the other four continued for 1324 weeks.

One patient with NSCLC tolerated $37.5 \mathrm{mg}$ for 3 cycles but was discontinued from the study due to diarrhea related to sunitinib and pemetrexed. One patient with anal cancer received sunitinib $50 \mathrm{mg}$ for 4 cycles but the pemetrexed dose had to be reduced to $375 \mathrm{mg} / \mathrm{m}^{2}$ in Cycles 2 through 4 . Another patient with metastatic synovial sarcoma received sunitinib $50 \mathrm{mg}$ for 3 cycles, but the pemetrexed dose had to be reduced to $400 \mathrm{mg} / \mathrm{m}^{2}$ in Cycles 2 and 3 .

The most common treatment-related non-hematologic AEs at the MTD on Schedule 2/1 are shown in Table 4; these events were predominantly mild to moderate in severity. In the original Schedule 2/1 MTD cohort, the most common non-hematologic AEs related to any study drug were fatigue/asthenia and diarrhea (both $n=4 ; 67 \%$ ). Among patients in the expansion cohort, fatigue/asthenia $(n=6 ; 100 \%)$, nausea, and decreased appetite (each $n=5$; $83 \%)$ were most common. Hematologic laboratory abnormalities on Schedule 2/1 at the MTD were grade 3/4 neutropenia, $n=5(83 \%)$; grade 3 leukopenia, $n=5$ (83\%); grade 3 lymphopenia, $n=1$ (17\%); grade $3 / 4$ thrombocytopenia, $n=3$ (50\%); and grade 3 anemia, $n=3$ $(50 \%)$. Serious AEs considered related to sunitinib treatment at the MTD included febrile neutropenia $(n=3)$, neutropenia (DLT), transient ischemic attack, anemia, and diarrhea (each $n=1$ ). No patient at the MTD had more than one serious AE related to sunitinib. 


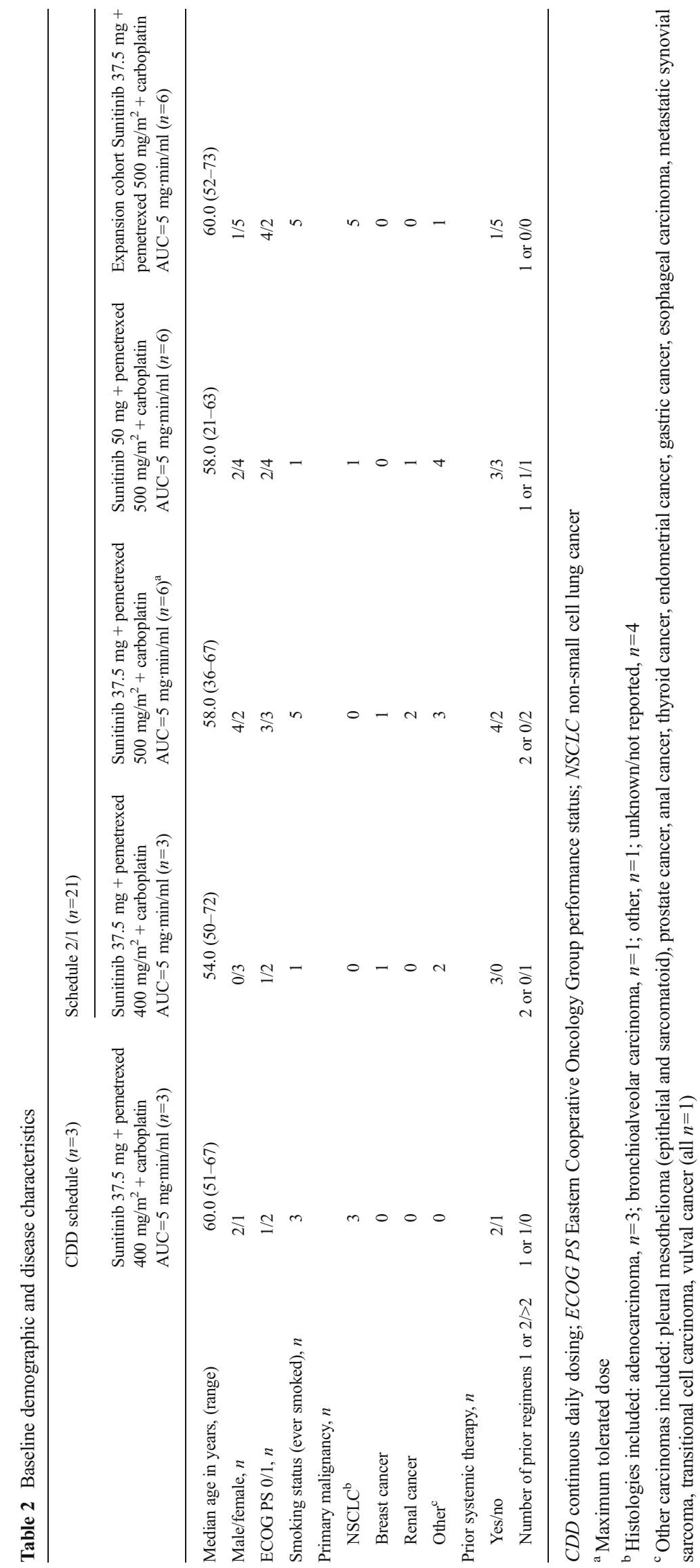


Table 3 Dose-limiting toxicities

\begin{tabular}{lllll}
$\begin{array}{l}\text { Sunitinib } \\
\text { dose }(\mathrm{mg})\end{array}$ & $\begin{array}{l}\text { Pemetrexed } \\
\text { dose }\left(\mathrm{mg} / \mathrm{m}^{2}\right)\end{array}$ & $\begin{array}{l}\text { Carboplatin dose } \\
(\text { AUC mg } \cdot \mathrm{min} / \mathrm{ml})\end{array}$ & $n$ & DLT details \\
\hline $\begin{array}{l}\text { Schedule } 2 / 1 \\
(n=21)\end{array}$ & & 3 & - \\
37.5 & 400 & 5 & 6 & Grade 3 neutropenia $(n=1)$ \\
$37.5^{\mathrm{b}}$ & $500^{\mathrm{b}}$ & $5^{\mathrm{b}}$ & 6 & Grade 3 thrombocytopenia $(n=1)$ \\
50 & 500 & 5 & & Grade 4 neutropenia $(n=2)$
\end{tabular}

$C D D$ continuous daily dosing; $D L T$ dose-limiting toxicity

${ }^{\text {a }}$ If a DLT was experienced by only one of the three patients at any dose level, the cohort was expanded to six patients. If none of the additional three patients experienced a DLT, the dose was escalated to the next level. If DLTs occurred in $\geq 2$ patients at any dose level, the dose level was deemed as having exceeded the MTD and the prior, lower dose level was further expanded (if only three patients were previously treated at that dose level). The MTD was defined as the dose level at which no more than one patient in a cohort of six experienced a DLT during the first 22 days of treatment of each schedule

${ }^{\mathrm{b}}$ Maximum tolerated dose (MTD)

\section{CDD schedule}

On the CDD schedule, two DLTs of grade 3 hand-foot syndrome $(n=1)$ and grade 4 neutropenia $(n=1)$ were observed with sunitinib $37.5 \mathrm{mg} /$ day + pemetrexed $400 \mathrm{mg} / \mathrm{m}^{2}+$ carboplatin $\mathrm{AUC}=5 \mathrm{mg} \cdot \mathrm{min} / \mathrm{ml}$ (Table 3 ). Because lower doses of sunitinib, pemetrexed, or carboplatin were considered unlikely to be efficacious, no further dose levels were investigated on the CDD schedule (thus the CDD MTD was not established) and the Schedule 2/1 MTD was selected for the expansion cohort.

On the CDD schedule, the median number of cycles of sunitinib, pemetrexed, and carboplatin received per patient was 6.0 (4-6), and dose reductions occurred in 2 patients (67\%) for sunitinib, and in 1 patient each for pemetrexed and carboplatin at dose level 1B (Table 1). Three patients on the CDD schedule $(100 \%)$ had at least one sunitinib dose delay of $1-3$ weeks, and 2 patients had a sunitinib dose reduction to $25 \mathrm{mg}$. Most treatmentrelated non-hematologic AEs were grade 1 or 2, with increased lacrimation being the most common $(n=3)$. Three serious AEs were considered related to sunitinib treatment: anemia, dehydration, and fatigue. Hematologic laboratory abnormalities were grade 4 neutropenia, $n=3(100 \%)$; grade 3/4 leukopenia, $n=3$ (100\%); grade 3 lymphopenia, $n=1$ (33\%); grade 3 anemia, $n=2(67 \%)$; and grade 4 thrombocytopenia, $n=1(33 \%)$.

\section{All cohorts}

Across all cohorts there were three deaths (one in the MTD cohort on Schedule 2/1 and two in the sunitinib $50 \mathrm{mg} /$ day + pemetrexed $500 \mathrm{mg} / \mathrm{m}^{2}+$ carboplatin $\mathrm{AUC}=5 \mathrm{mg} \cdot \mathrm{min} / \mathrm{ml}$
Table 4 Treatment-related (sunitinib, pemetrexed or carboplatin) nonhematologic adverse events of special interest or experienced by $\geq 2$ patients treated at the maximum tolerated dose on Schedule 2/1

\begin{tabular}{|c|c|c|c|c|}
\hline \multirow[t]{2}{*}{ Adverse event } & \multicolumn{2}{|c|}{$\begin{array}{l}\text { Sunitinib } 37.5 \mathrm{mg}+ \\
\text { pemetrexed } 500 \mathrm{mg} / \\
\mathrm{m}^{2}+\text { carboplatin } \\
\text { AUC }=5 \mathrm{mg} \cdot \mathrm{min} / \mathrm{ml} \\
\text { (original cohort, } n=6 \text { ) }\end{array}$} & \multicolumn{2}{|c|}{$\begin{array}{l}\text { Sunitinib } 37.5 \mathrm{mg}+ \\
\text { pemetrexed } 500 \mathrm{mg} / \mathrm{m}^{2}+ \\
\text { carboplatin } \\
\text { AUC }=5 \mathrm{mg} \cdot \mathrm{min} / \mathrm{ml} \\
\text { (expansion cohort, } n=6 \text { ) }\end{array}$} \\
\hline & $\begin{array}{l}\text { Grade } 3 / 4 \\
n(\%)\end{array}$ & $\begin{array}{l}\text { Total } \\
n(\%)\end{array}$ & $\begin{array}{l}\text { Grade } 3 / 4 \\
n(\%)\end{array}$ & $\begin{array}{l}\text { Total } \\
n(\%)\end{array}$ \\
\hline Fatigue/asthenia & $1(17)$ & $4(67)$ & $1(17)$ & $6(100)$ \\
\hline Decreased appetite & 0 & $2(33)$ & $1(17)$ & $5(83)$ \\
\hline Nausea & 0 & $1(17)$ & $1(17)$ & $5(83)$ \\
\hline Diarrhea & $1(17)$ & $4(67)$ & $1(17)$ & $4(67)$ \\
\hline Edema/swelling ${ }^{\mathrm{a}}$ & 0 & $2(33)$ & 0 & $4(67)$ \\
\hline Dyspepsia & 0 & $1(17)$ & 0 & $3(50)$ \\
\hline Dehydration & 0 & 0 & $2(33)$ & $3(50)$ \\
\hline Hypertension & 0 & $2(33)$ & 0 & $2(33)$ \\
\hline Skin/subcutaneous tissue disorders ${ }^{\mathrm{b}}$ & 0 & $2(33)$ & 0 & $2(33)$ \\
\hline Weight decreased & 0 & $1(17)$ & 0 & $2(33)$ \\
\hline Chills & 0 & 0 & 0 & $2(33)$ \\
\hline Vomiting & 0 & 0 & 0 & $2(33)$ \\
\hline Yellow skin & 0 & 0 & 0 & $2(33)$ \\
\hline Hypomagnesemia & 0 & $2(33)$ & 0 & $1(17)$ \\
\hline $\begin{array}{l}\text { Stomatitis/oral discomfort/ } \\
\text { related oral syndromes }\end{array}$ & 0 & $2(33)$ & 0 & $1(17)$ \\
\hline Paresthesia/neuropathy ${ }^{\mathrm{d}}$ & 0 & $1(17)$ & 0 & $1(17)$ \\
\hline Constipation & 0 & $2(33)$ & 0 & 0 \\
\hline Flatulence & 0 & $2(33)$ & 0 & 0 \\
\hline Jaundice & 0 & $2(33)$ & 0 & 0 \\
\hline
\end{tabular}

No grade 5 adverse events were reported at the MTD on Schedule 2/1

MTD maximum tolerated dose

${ }^{a}$ Edema/swelling is any event having a preferred term that contains edema or swelling

${ }^{\mathrm{b}}$ Skin/subcutaneous tissue disorders is any event having a preferred term that contains erythema or hyperkeratosis or rash or skin exfoliation or skin hyperpigmentation

${ }^{\mathrm{c}}$ Stomatitis/oral discomfort/related oral syndromes is any event having a preferred term equal to aphthous stomatitis, gingival pain, gingival ulceration, gingivitis, glossodynia, glossitis, mouth ulceration, mucosal dryness, mucosal inflammation, mucosal ulceration, oral discomfort, oral mucosal blistering, oral pain, stomatitis, swollen tongue, tongue blistering, tongue edema, or tongue ulceration

${ }^{\mathrm{d}}$ Paresthesia/neuropathy is any event having a preferred term that contains paresthesia or neuropathy

cohort on Schedule 2/1). All deaths occurred during followup, more than 28 days after the last dose of study medication, and were considered related to the disease under study.

\section{Pharmacokinetics}

Pharmacokinetic data revealed no clinically significant drugdrug interactions with the triple combination of sunitinib, pemetrexed, and carboplatin. The PK profile of sunitinib plus 
SU12662 in the presence of pemetrexed/carboplatin was compared with historical controls since no data were collected for sunitinib administered alone (Table 5). Samples from the last 3 patients enrolled in the Schedule 2/1 MTD cohort showed that the geometric mean ratios (triple combination relative to sunitinib alone) for sunitinib $\mathrm{C}_{\max }$ and $\mathrm{AUC}_{24}$ were 1.12 and 1.38 , respectively. These data suggest that the PK of sunitinib when co-administered with pemetrexed and carboplatin were similar to when it was administered alone. The geometric mean ratios (triple combination relative to pemetrexed/carboplatin alone) for pemetrexed $\mathrm{C}_{\max }$ and $\mathrm{AUC}_{\infty}$ were 1.20 and 1.03 , respectively; for total platinum $\mathrm{C}_{\max }$ and $\mathrm{AUC}_{24}$ they were 0.97 and 1.00; and for free platinum $\mathrm{C}_{\max }$ and $\mathrm{AUC}_{24}$ they were 0.94 and 0.95 (Table 5). Based on these data, the addition of sunitinib to pemetrexed and carboplatin did not appear to affect the PK of pemetrexed or carboplatin. Individual patient plasma concentration-time profiles are presented in Fig. 1.

\section{Antitumor activity}

\section{Schedule 2/1}

Of 21 evaluable patients treated on Schedule 2/1, a confirmed partial response was observed in 4 patients (objective response rate [ORR] $19.0 \%$ ) and stable disease $\geq 8$ weeks was reported in 9 patients $(42.9 \%)$. The patients with a partial response had primary diagnoses of breast cancer (sunitinib $37.5 \mathrm{mg}+$ pemetrexed $400 \mathrm{mg} / \mathrm{m}^{2}+$ carboplatin $\mathrm{AUC}=5-$ $\mathrm{mg} \cdot \mathrm{min} / \mathrm{ml}$ ), esophageal carcinoma (sunitinib $37.5 \mathrm{mg}+$ pemetrexed $500 \mathrm{mg} / \mathrm{m}^{2}+$ carboplatin $\mathrm{AUC}=5 \mathrm{mg} \cdot \mathrm{min} / \mathrm{ml}$ ), gastric cancer (sunitinib $50 \mathrm{mg}+$ pemetrexed $500 \mathrm{mg} / \mathrm{m}^{2}+$ carboplatin AUC $=5 \mathrm{mg} \cdot \mathrm{min} / \mathrm{ml}$ ), and NSCLC, tumor histology not otherwise specified (NOS; sunitinib $50 \mathrm{mg}+$ pemetrexed $500 \mathrm{mg} / \mathrm{m}^{2}+$ carboplatin $\mathrm{AUC}=5 \mathrm{mg} \cdot \mathrm{min} / \mathrm{ml}$ ).

Of 5 patients with NSCLC treated at the Schedule 2/1 MTD who were evaluable based on measurable disease at baseline, three had stable disease $\geq 8$ weeks, one had progressive disease, and in one case the response could not be evaluated (stable disease but $<8$ weeks for response evaluation) (Table 6). As part of a continuation protocol, sunitinib (25-50 $\mathrm{mg}$ /day) was administered to 3 patients with NSCLC upon completion of 6 cycles of sunitinib + pemetrexed + carboplatin in the original study, or at the investigator's discretion. Best overall responses (taking into account time spent on both the original and continuation protocols) were partial response in 1 patient maintained for 6.9 months and stable disease maintained for 3.5 months and 7.9 months in the other 2 patients. Overall survival times were greater than 10.0, 6.9, and 10.6 months (all 3 patients were alive at last data collection point).

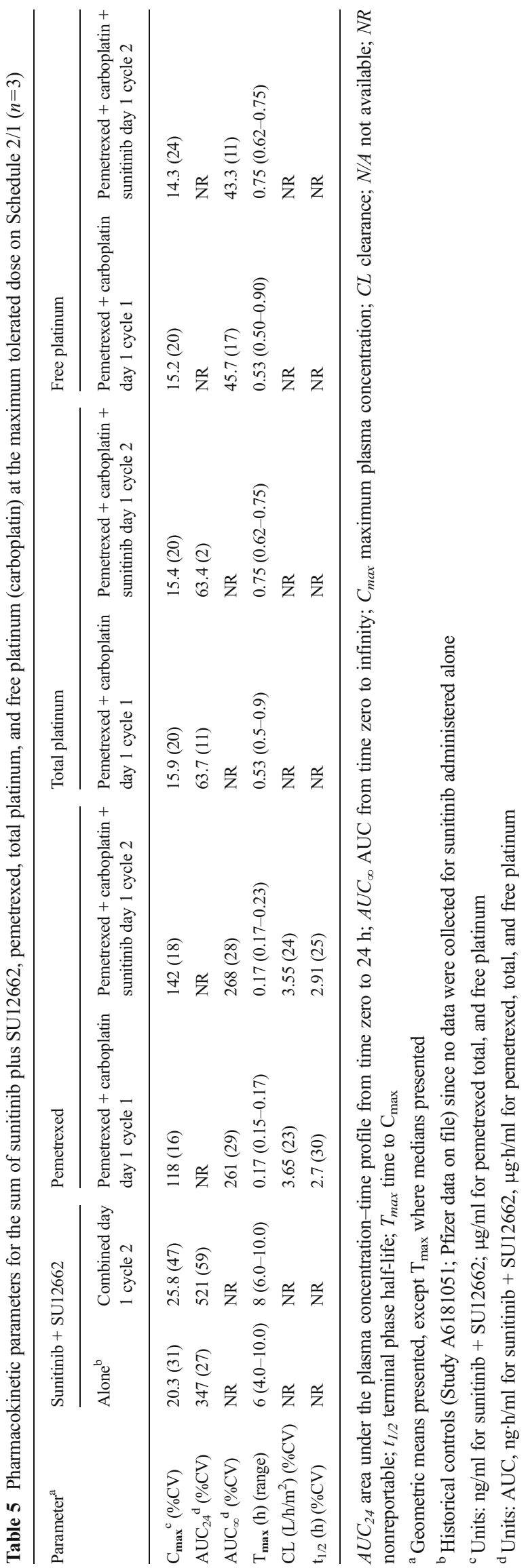


(a)

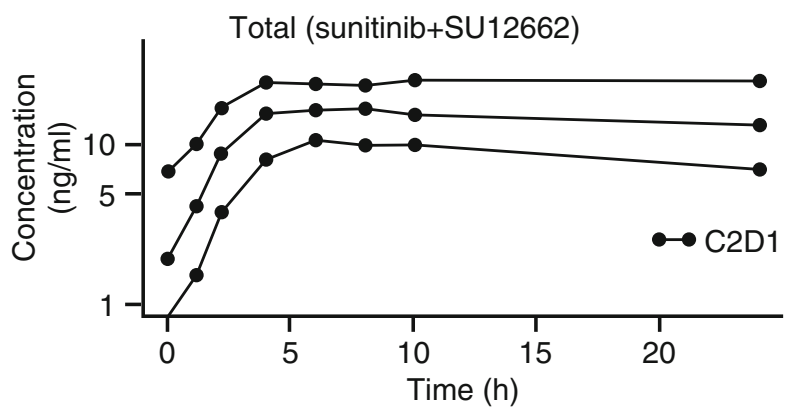

(c)

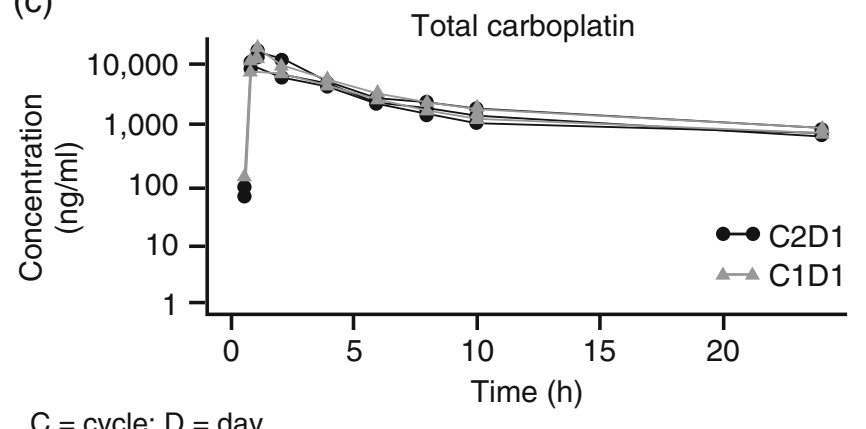

$\mathrm{C}=$ cycle; $\mathrm{D}=$ day

Fig. 1 Individual plasma concentration-time profiles for a the sum of sunitinib plus SU12662 in combination with pemetrexed/carboplatin on day 1 of cycle $2(n=3)$, b pemetrexed $(n=3)$, $\mathbf{c}$ total platinum $(n=3)$, and $\mathbf{d}$

\section{CDD schedule}

All 3 evaluable patients treated with the triple combination on the CDD schedule had stable disease $\geq 8$ weeks as the best confirmed objective response.

\section{Discussion}

Data from preclinical tumor models suggest that adding an antiangiogenic agent to chemotherapy may improve efficacy
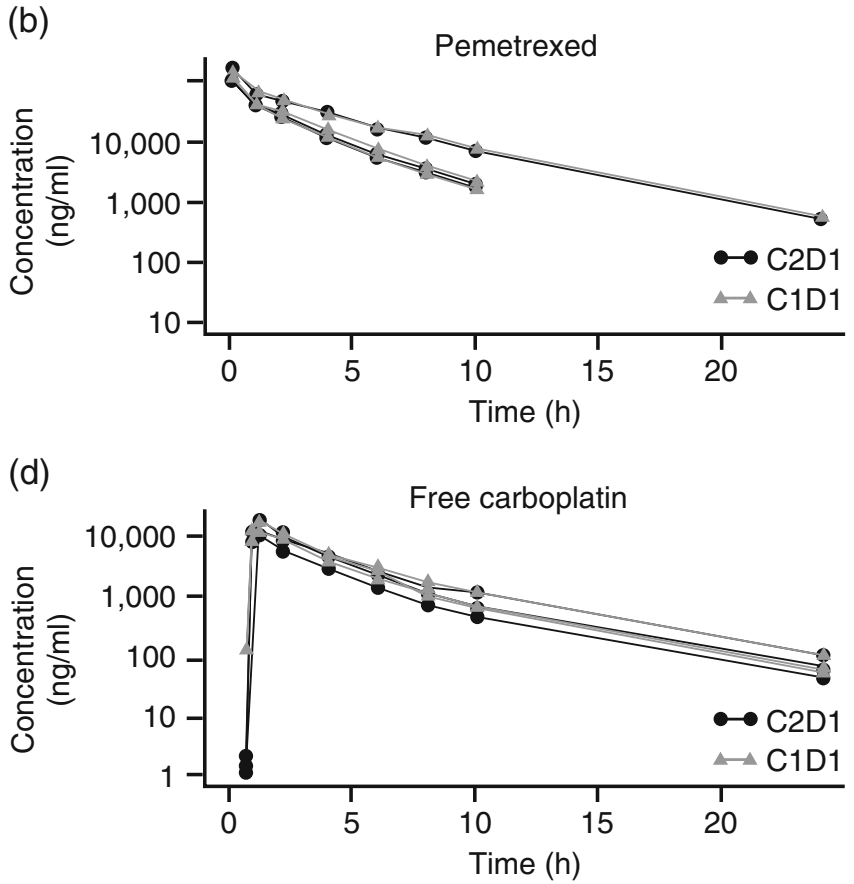

free platinum $(n=3)$. Pemetrexed and carboplatin are shown alone and in combination with sunitinib at the maximum tolerated dose on Schedule 2/1

[26-28]. Pemetrexed, sunitinib, and carboplatin are well tolerated individually and in combination, and have demonstrated antitumor activity in a broad range of malignancies, including NSCLC [12, 13, 22, 25]. The combination of pemetrexed and sunitinib has previously been reported to have promising tolerability and the potential for clinical benefit in patients with solid tumors, including NSCLC [34]. However, as noted above, a randomized phase II study of pemetrexed versus sunitinib versus the combination conducted by CALGB suggested that single agent pemetrexed was superior to either arm containing sunitinib [30]. Sunitinib was administered on a

Table 6 Responses in patients with NSCLC (all cohorts; $n=8$ )

\begin{tabular}{|c|c|c|c|c|c|}
\hline Patient & NSCLC histology & Cohort $^{\mathrm{a}}$ & Best response & $\begin{array}{l}\text { Rolled over onto } \\
\text { continuation protocol? }\end{array}$ & $\begin{array}{l}\text { Total time on treatment (weeks; up to } \\
\text { July } 2011 \text { for continuation patients }{ }^{\text {b }} \text { ) }\end{array}$ \\
\hline 1 & Unknown & Schedule $2 / 1$, dose level B3 & Partial response & $\mathrm{Y}$ & 39.6 \\
\hline 2 & Other & CDD, dose level B1 & Stable disease $\geq 8$ weeks & $\mathrm{Y}$ & 40 \\
\hline 3 & Other & CDD, dose level B1 & Stable disease $\geq 8$ weeks & $\mathrm{N}$ & 20.6 \\
\hline 4 & Adenocarcinoma & Schedule 2/1, MTD (expansion) & Stable disease $\geq 8$ weeks & $\mathrm{Y}$ & 20.9 \\
\hline 5 & Adenocarcinoma & Schedule 2/1, MTD (expansion) & Stable disease $\geq 8$ weeks & $\mathrm{N}$ & 21.7 \\
\hline 6 & Bronchioloalveolar & Schedule 2/1, MTD (expansion) & Stable disease $\geq 8$ weeks & $\mathrm{N}$ & 8.6 \\
\hline 7 & Adenocarcinoma & Schedule 2/1, MTD (expansion) & Progressive disease & $\mathrm{N}$ & 8.6 \\
\hline 8 & Unknown & Schedule $2 / 1$, MTD (expansion) & Not evaluable & $\mathrm{N}$ & 2.1 \\
\hline
\end{tabular}

$C D D$ continuous daily dosing; NSCLC non-small cell lung cancer

${ }^{\text {a }}$ Dose levels are described in Table 1

${ }^{\mathrm{b}}$ All rollover patients were still alive at time of data collection 
$37.5 \mathrm{mg} /$ day CDD schedule and the combination was associated with greater hematologic toxicity than either agent alone.

This phase I study established the MTD and overall safety of the triple combination of sunitinib plus pemetrexed and carboplatin in patients with advanced solid malignancies. The MTD on Schedule 2/1 was determined to be sunitinib $37.5 \mathrm{mg} /$ day + pemetrexed $500 \mathrm{mg} / \mathrm{m}^{2} \mathrm{q} 3 \mathrm{w}+$ carboplatin $\mathrm{AUC}=5 \mathrm{mg} \cdot \mathrm{min} / \mathrm{ml} \mathrm{q} 3 \mathrm{w}$. The MTD cohort was expanded to further explore the feasibility, tolerability, and early activity of this triple combination for the treatment of advanced NSCLC or mesothelioma. The MTD on the CDD schedule was not established, as the first dose level tested on this schedule (sunitinib $37.5 \mathrm{mg} /$ day + pemetrexed $400 \mathrm{mg} / \mathrm{m}^{2} \mathrm{q} 3 \mathrm{w}+$ carboplatin $\mathrm{AUC}=5 \mathrm{mg} \cdot \mathrm{min} / \mathrm{ml}$ ) was poorly tolerated due to myelosuppression. As preclinical models and data on minimum inhibitory concentrations suggest that the minimum effective dose is in the range of $37.5 \mathrm{mg} /$ day [2], it was not felt that the exploration of a lower dose schedule would lead to clinically significant activity, considering the need to use suboptimal doses of each individual drug and the clinical experience of other groups using sunitinib alone or in combination with other chemotherapy regimens [36, 37]. Although there were no PK interactions, toxicities appeared additive (particularly in the form of myelosuppression), suggesting overlapping pharmacodynamic effects. It should be noted that full PK profiles for sunitinib, SU12662, pemetrexed, and carboplatin were only obtained from the last 3 patients in the Schedule 2/1 MTD cohort. In the investigators' judgment, the drug was not sufficiently tolerated to proceed with dose escalation and lower doses would not provide a clinical benefit. However, data from these 3 patients were consistent with historical controls from another study in similar patient populations which did not indicate major discrepancies. There is no preclinical evidence suggesting drug-drug interactions, and the pharmacologic profiles of pemetrexed, sunitinib and carboplatin do not predict any elimination interactions when the drugs are used in combination. Sunitinib is metabolized primarily by CYP3A4, which does not play a role in the elimination of carboplatin or pemetrexed. Furthermore, drug-drug interactions at the absorption level can be ruled out as carboplatin and pemetrexed were administered intravenously.

The Schedule 2/1 MTD was generally tolerable and clinically manageable on both sunitinib treatment schedules, with most non-hematologic toxicities being mild or moderate (grade 1 or 2 ), and similar to those reported with either single-agent sunitinib or pemetrexed combined with carboplatin in advanced NSCLC $[12,13,38]$.

Myelosuppression was a common toxicity on the 2/1 dosing schedule, as anticipated. Sunitinib as a single agent has been associated with myelosuppression in a small proportion of patients [17, 18, 39]. One possible explanation is the inhibition of c-KIT, FLT3, and colony-stimulating factor receptor (c-fms), which may play a role in recovery of blood cells following myelosuppressive chemotherapy [40].

Hematologic toxicities such as thrombocytopenia and anemia are common AEs of treatment with carboplatin and pemetrexed monotherapy. In the current study, hematologic toxicities occurred at a greater rate than expected with carboplatin and pemetrexed alone [38, 41]. The DLTs and MTD were determined during the first cycle of treatment; however, the initial tolerability of these doses was not uniformly sustained, as most patients at the Schedule 2/1 MTD required subsequent sunitinib dose delays or reductions $(75 \%$ and $50 \%$, respectively). A median of 5.0 (2-6) cycles of the triple combination was administered in the original Schedule 2/1 MTD cohort, and a median of 3.5 (1-4) cycles was administered in the expansion cohort, which compared favorably with the cycles reported previously for combinations of pemetrexed with platinum agents (a median of 3 cycles of pemetrexed combined with cisplatin or carboplatin has been reported in previously treated patients with NSCLC [42]). Pharmacokinetic analyses revealed no clinically significant drug-drug interactions following co-administration of sunitinib with pemetrexed plus carboplatin.

The toxicity of the combination was broadly similar to previous reports of sunitinib plus other types of chemotherapy. Myelosuppression, fatigue, and diarrhea occurred frequently and often led to dose adjustments in studies of sunitinib combined with paclitaxel [43, 44], pemetrexed [45], carboplatin/ paclitaxel/bevacizumab [37], gemcitabine/cisplatin [40], FOLFIRI [46], or modified FOLFOX6 [47]. Significant toxicities have also been observed with other VEGFR-TKIs combined with chemotherapy. Rates of hematological toxicities and diarrhea were elevated in studies of sorafenib combined with docetaxel/cisplatin [48], gemcitabine/cisplatin [49], or paclitaxel/carboplatin [50]. Similarly, hematologic abnormalities and diarrhea were commonly observed when axitinib was combined with FOLFIRI [51] or docetaxel [52], and the combination of axitinib plus bevacizumab and FOLFOX was reported to markedly raise the incidence of hypertension [51].

In the current study, the ORR on Schedule 2/1 was 4/21 (19\%). Given the small number of evaluable patients, and that responses were observed in patients with different tumor types, it is not possible to draw a definitive conclusion on the response rate. However, the observed rate compares favorably with the ORR for single-agent pemetrexed (4\% [22]) and carboplatin plus pemetrexed (9\% [39]) observed in larger studies. Of the three patients with NSCLC who entered the continuation study, one patient with NSCLC NOS had a partial response (lasting 6.9 months) and two patients with NSCLC NOS and adenocarcinoma maintained stable disease for 7.9 and 3.5 months, respectively.

In summary, although the MTD of sunitinib on Schedule 2/1 in combination with pemetrexed and carboplatin was established, dose adjustments were often required as a result of 
myelosuppression, especially in patients with NSCLC, making it difficult to maintain a pharmacologically active sunitinib dose. Although one response was observed in a patient with NSCLC started at the highest sunitinib dose (50 mg), this dose could not be sustained in this patient group. However, $37.5 \mathrm{mg}$ was better tolerated in patients with other tumor types, and clinical responses were observed in patients with esophageal carcinoma, breast cancer, and gastric carcinoma. Further exploration of this combination in solid tumors is warranted.

Acknowledgments We would like to thank all of the participating patients and their families, as well as the global network of investigators, research nurses, study coordinators, and operations staff.

This study was sponsored by Pfizer Inc. Medical writing support was provided by Siân Marshall at ACUMED ${ }^{\circledR}$ (Tytherington, UK) and was funded by Pfizer Inc.

Conflict of interest N Blais has received research funding from Pfizer. DR Camidge has served as a paid advisor to Pfizer and Eli Lilly, and has received research funding from Eli Lilly. DJ Jonker has no conflicts to disclose. D Soulières has received honoraria from Pfizer. SA Laurie has served as a paid advisor to Pfizer. SG Diab has no conflicts to disclose. A Ruiz-Garcia, A Thall, K Zhang, and R Chao are employees of Pfizer Oncology and hold stock in Pfizer, the manufacturer of sunitinib. LQ Chow has received research funding from Pfizer.

Open Access This article is distributed under the terms of the Creative Commons Attribution License which permits any use, distribution, and reproduction in any medium, provided the original author(s) and the source are credited.

\section{References}

1. Abrams TJ, Lee LB, Murray LJ, Pryer NK, Cherrington JM (2003) SU11248 inhibits KIT and platelet-derived growth factor receptor beta in preclinical models of human small cell lung cancer. Mol Cancer Ther 2:471-478

2. Chow LQ, Eckhardt SG (2007) Sunitinib: from rational design to clinical efficacy. J Clin Oncol 25:884-896

3. Kim DW, Jo YS, Jung HS, Chung HK, Song JH, Park KC, Park SH, Hwang JH, Rha SY, Kweon GR, Lee SJ, Jo KW, Shong M (2006) An orally administered multitarget tyrosine kinase inhibitor, SU11248, is a novel potent inhibitor of thyroid oncogenic RET/papillary thyroid cancer kinases. J Clin Endocrinol Metab 91:4070-4076

4. Mendel DB, Laird AD, Xin X, Louie SG, Christensen JG, Li G, Schreck RE, Abrams TJ, Ngai TJ, Lee LB, Murray LJ, Carver J, Chan E, Moss KG, Haznedar JO, Sukbuntherng J, Blake RA, Sun L, Tang C, Miller T, Shirazian S, McMahon G, Cherrington JM (2003) In vivo antitumor activity of SU11248, a novel tyrosine kinase inhibitor targeting vascular endothelial growth factor and plateletderived growth factor receptors: determination of a pharmacokinetic/ pharmacodynamic relationship. Clin Cancer Res 9:327-337

5. Murray LJ, Abrams TJ, Long KR, Ngai TJ, Olson LM, Hong W, Keast PK, Brassard JA, O'Farrell AM, Cherrington JM, Pryer NK (2003) SU11248 inhibits tumor growth and CSF-1R-dependent osteolysis in an experimental breast cancer bone metastasis model. Clin Exp Metastasis 20:757-766

6. O'Farrell AM, Abrams TJ, Yuen HA, Ngai TJ, Louie SG, Yee KW, Wong LM, Hong W, Lee LB, Town A, Smolich BD, Manning WC, Murray LJ, Heinrich MC, Cherrington JM (2003) SU11248 is a novel FLT3 tyrosine kinase inhibitor with potent activity in vitro and in vivo. Blood 101:3597-3605

7. Hasumi Y, Klosowska-Wardega A, Furuhashi M, Ostman A, Heldin $\mathrm{CH}$, Hellberg $\mathrm{C}$ (2007) Identification of a subset of pericytes that respond to combination therapy targeting PDGF and VEGF signaling. Int J Cancer 121:2606-2614

8. Koukourakis MI, Giatromanolaki A, O’Byrne KJ, Comley M, Whitehouse RM, Talbot DC, Gatter KC, Harris AL (2007) Plateletderived endothelial cell growth factor expression correlates with tumour angiogenesis and prognosis in non-small-cell lung cancer. Br J Cancer 75:477-481

9. Shikada Y, Yonemitsu Y, Koga T, Onimaru M, Nakano T, Okano S, Sata S, Nakagawa K, Yoshino I, Maehara Y, Sueishi K (2005) Platelet-derived growth factor-AA is an essential and autocrine regulator of vascular endothelial growth factor expression in non-small cell lung carcinomas. Cancer Res 65:7241-7248

10. Yuan A, Yu CJ, Kuo SH, Chen WJ, Lin FY, Luh KT, Yang PC, Lee YC (2001) Vascular endothelial growth factor 189 mRNA isoform expression specifically correlates with tumor angiogenesis, patient survival, and postoperative relapse in non-small-cell lung cancer. J Clin Oncol 19:432-441

11. Sutent PI (2012) SUTENT, summary of product characteristics. Pfizer Inc., New York

12. Socinski MA, Novello S, Brahmer JR, Rosell R, Sanchez JM, Belani CP, Govindan R, Atkins JN, Gillenwater HH, Pallares C, Tye L, Selaru P, Chao RC, Scagliotti GV (2008) Multicenter, phase II trial of sunitinib in previously treated, advanced non-small-cell lung cancer. J Clin Oncol 26:650-656

13. Novello S, Scagliotti GV, Rosell R, Socinski MA, Brahmer J, Atkins J, Pallares C, Burgess R, Tye L, Selaru P, Wang E, Chao R, Govindan R (2009) Phase II study of continuous daily sunitinib dosing in patients with previously treated advanced non-small cell lung cancer. Br J Cancer 101:1543-1548

14. Kulke M, Lenz HJ, Meropol N, Posey J, Ryan DP, Picus J, Bergsland E, Stuart K, Tye L, Huang X, Li JZ, Baum CM, Fuchs CS (2008) Activity of sunitinib in patients with advanced neuroendocrine tumors. J Clin Oncol 26:3403-3410

15. Raymond E, Dahan L, Raoul J-L, Bang YJ, Borbath I, LombardBohas C, Valle J, Metrakos P, Smith D, Vinik A, Chen JS, Hörsch D, Hammel P, Wiedenmann B, Van Cutsem E, Patyna S, Lu DR, Blanckmeister C, Chao R, Ruszniewski P (2011) Sunitinib malate for the treatment of pancreatic neuroendocrine tumors. N Engl J Med 364:501-513

16. Escudier B, Roigas J, Gillessen S, Harmenberg U, Srinivas S, Mulder SF, Fountzilas G, Peschel C, Flodgren P, Maneval EC, Chen I, Vogelzang NJ (2009) Phase II study of sunitinib administered in a continuous once-daily dosing regimen in patients with cytokinerefractory metastatic renal cell carcinoma. J Clin Oncol 27:4068-4075

17. George S, Blay JY, Casali PG, Le Cesne A, Stephenson P, Deprimo SE, Harmon CS, Law CN, Morgan JA, Ray-Coquard I, Tassell V, Cohen DP, Demetri GD (2009) Clinical evaluation of continuous daily dosing of sunitinib malate in patients with advanced gastrointestinal stromal tumour after imatinib failure. Eur J Cancer 45:19591968

18. Motzer RJ, Rini BI, Bukowski RM, Curti BD, George DJ, Hudes GR, Redman BG, Margolin KA, Merchan JR, Wilding G, Ginsberg MS, Bacik J, Kim ST, Baum CM, Michaelson MD (2006) Sunitinib in patients with metastatic renal cell carcinoma. JAMA 295:25162524

19. Motzer RJ, Michaelson MD, Rosenberg J, Bukowski RM, Curti BD, George DJ, Hudes GR, Redman BG, Margolin KA, Wilding G (2007) Sunitinib efficacy against advanced renal cell carcinoma. J Urol 178:1883-1887

20. Hanauske AR, Chen V, Paoletti P, Niyikiza C (2001) Pemetrexed disodium: a novel antifolate clinically active against multiple solid tumors. Oncologist 6:363-373 
21. Hanna N, Shepherd FA, Fossella FV, Pereira JR, De Marinis F, von Pawel J, Gatzemeier U, Tsao TC, Pless M, Muller T, Lim HL, Desch C, Szondy K, Gervais R, Shaharyar, Manegold C, Paul S, Paoletti P, Einhorn L, Bunn PA Jr (2004) Randomized phase III trial of pemetrexed versus docetaxel in patients with non-small-cell lung cancer previously treated with chemotherapy. J Clin Oncol 22:1589-1597

22. Russo F, Bearz A, Pampaloni G, the Investigators of the Italian Pemetrexed Monotherapy of NSCLC Group (2008) Pemetrexed single agent chemotherapy in previously treated patients with locally advanced or metastatic non-small cell lung cancer. BMC Cancer $8: 216$

23. Ceresoli GL, Zucali PA, Favaretto AG, Grossi F, Bidoli P, Del Conte G, Ceribelli A, Bearz A, Morenghi E, Cavina R, Marangolo M, Parra HJ, Santoro A (2006) Phase II study of pemetrexed plus carboplatin in malignant pleural mesothelioma. J Clin Oncol 24:1443-1448

24. Socinski M, Weissman C, Hart LL, Beck JT, Choksi JK, Hanson JP, Prager D, Monberg MJ, Ye Z, Obasaju CK (2006) Randomized phase II trial of pemetrexed combined with either cisplatin or carboplatin in untreated extensive-stage small-cell lung cancer. J Clin Oncol $24: 4840-4847$

25. Zinner RG, Fossella FV, Gladish GW, Glisson BS, Blumenschein GR Jr, Papadimitrakopoulou VA, Pisters KM, Kim ES, Oh YW, Peeples BO, Ye Z, Curiel RE, Obasaju CK, Hong WK, Herbst RS (2005) Phase II study of pemetrexed in combination with carboplatin in the first-line treatment of advanced nonsmall cell lung cancer. Cancer 104:2449-2456

26. Christensen JG, Hall C, Hollister BA (2008) Antitumor efficacy of sunitinib malate in concurrent and sequential combinations with standard chemotherapeutic agents in non-small cell lung cancer (NSCLC) nonclinical models. Proceedings of the 99th Annual Meeting of the American Association for Cancer Research (abstract)

27. Huber PE, Bischof M, Jenne J, Heiland S, Peschke P, Saffrich R, Gröne HJ, Debus J, Lipson KE, Abdollahi A (2005) Trimodal cancer treatment: beneficial effects of combined antiangiogenesis, radiation, and chemotherapy. Cancer Res 65:3643-3655

28. Rosen L (2000) Antiangiogenic strategies and agents in clinical trials. Oncologist 5(Suppl 1):20-27

29. Figg WD, Folkman J (2008) Angiogenesis: an integrative approach from science to medicine. Springer, New York

30. Heist RS, Wang XF, Hodgson L, Otterson GA, Stinchcombe T, Vokes EE, Socinski AA (2012) CALGB 30704: a randomized phase II study to assess the efficacy of pemetrexed or sunitinib or pemetrexed plus sunitinib in the second-line treatment of advanced non-small cell lung cancer (NSCLC). J Clin Oncol 30(suppl; abstr 7513)

31. Reck M, von Pawel J, Zatloukal P, Ramlau R, Gorbounova V, Hirsh V, Leighl N, Mezger J, Archer V, Moore N, Manegold C (2009) Phase III trial of cisplatin plus gemcitabine with either placebo or bevacizumab as first-line therapy for nonsquamous non-small-cell lung cancer: AVAil. J Clin Oncol 27:1227-1234

32. Sandler A, Gray R, Perry MC, Brahmer J, Schiller JH, Dowlati A, Lilenbaum R, Johnson DH (2006) Paclitaxel-carboplatin alone or with bevacizumab for non-small-cell lung cancer. N Engl J Med $355: 2542-2550$

33. Hurwitz H, Fehrenbacher L, Novotny W, Cartwright T, Hainsworth J, Heim W, Berlin J, Baron A, Griffing S, Holmgren E, Ferrara N, Fyfe G, Rogers B, Ross R, Kabbinavar F (2004) Bevacizumab plus irinotecan, fluorouracil, and leucovorin for metastatic colorectal cancer. N Engl J Med 350:2335-2342

34. Chow LQ, Blais N, Jonker DJ, Laurie SA, Diab SG, Canil C, McWilliam M, Thall A, Ruiz-Garcia A, Zhang K, Tye L, Chao RC, Camidge DR (2012) A phase I dose-escalation and pharmacokinetic study of sunitinib in combination with pemetrexed in patients with advanced solid malignancies, with an expanded cohort in non-small cell lung cancer. Cancer Chemother Pharmacol 69:709-722
35. Therasse P, Arbuck SG, Eisenhauer EA, Wanders J, Kaplan RS, Rubinstein L, Verweij J, Van Glabbeke M, van Oosterom AT, Christian MC, Gwyther SG (2000) New guidelines to evaluate the response to treatment in solid tumors. J Natl Cancer Inst 92:205-216

36. Gervais R, Hainsworth JD, Blais N, Besse B, Laskin J, Hamm JT, Lipton A, Albain KS, Masters GA, Natale RB, Selaru P, Kim ST, Chao RC, Page RD (2011) Phase II study of sunitinib as maintenance therapy in patients with locally advanced or metastatic non-small cell lung cancer. Lung Cancer 74:474-480

37. Socinski MA, Scappaticci FA, Samant M, Kolb MM, Kozloff MF (2010) Safety and efficacy of combining sunitinib with bevacizumab + paclitaxel/carboplatin in non-small cell lung cancer. J Thorac Oncol 5:354-360

38. Kim HS, Lee GW, Kim JH, Kim HY, Kwon JH, Song HH, Kim HJ, Jung JY, Jang G, Choi DR, Park SM, Shin TR, Lee HS, Zang DY (2010) A phase II study of pemetrexed and carboplatin as a salvage therapy for platinum-pretreated patients with non-small cell lung cancer. Lung Cancer 70:71-76

39. Burstein HJ, Elias AD, Rugo HS, Cobleigh MA, Wolff AC, Eisenberg PD, Lehman M, Adams BJ, Bello CL, DePrimo SE, Baum CM, Miller KD (2008) Phase II study of sunitinib malate, an oral multitargeted tyrosine kinase inhibitor, in patients with metastatic breast cancer previously treated with an anthracycline and a taxane. J Clin Oncol 26:1810-1816

40. Reck M, Frickhofen N, Cedres S, Gatzemeier U, Heigener D, Fuhr H-G, Thall A, Lanzalone S, Stephenson P, Ruiz-Garcia A, Chao R, Felip E (2010) Sunitinib in combination with gemcitabine plus cisplatin for advanced non-small cell lung cancer: a phase I doseescalation study. Lung Cancer 70:180-187

41. Smit EF, Burgers SA, Biesma B, Smit HJ, Eppinga P, Dingemans AM, Joerger M, Schellens JH, Vincent A, van Zandwijk N, Groen HJ (2009) Randomized phase II and pharmacogenetic study of pemetrexed compared with pemetrexed plus carboplatin in pretreated patients with advanced non-small-cell lung cancer. J Clin Oncol 27:2038-2045

42. Zhang GZ, Jiao SC, Meng ZT (2010) Pemetrexed plus cisplatin/ carboplatin in previously treated locally advanced or metastatic non-small cell lung cancer patients. J Exp Clin Cancer Res 29:38

43. Kozloff M, Chuang E, Starr A, Gowland PA, Cataruozolo PE, Collier M, Verkh L, Huang X, Kern KA, Miller K (2010) An exploratory study of sunitinib plus paclitaxel as firstline treatment for patients with advanced breast cancer. Ann Oncol 21:14361441

44. Robert NJ, Saleh MN, Paul D, Generali D, Gressot L, Copur MS, Brufsky AM, Minton SE, Giguere JK, Smith JW 2nd, Richards PD, Gernhardt D, Huang X, Liau KF, Kern KA, Davis J (2011) Sunitinib plus paclitaxel versus bevacizumab plus paclitaxel for first-line treatment of patients with advanced breast cancer: a phase III, randomized, open-label trial. Clin Breast Cancer 11:82-92

45. Okamoto I, Shimizu T, Miyazaki M, Tsurutani J, Ichikawa Y, Terashima M, Takeda M, Fumita S, Ohki E, Kimura N, Hashimoto J, Nakagawa K (2012) Feasibility study of two schedules of sunitinib in combination with pemetrexed in patients with advanced solid tumors. Invest New Drugs 30:639-646

46. Mross K, Büchert M, Fasol U, Jaehde U, Kanefendt F, Strumberg D, Arends J, Hense J, Moritz B, Fischer R, Scheulen ME (2011) A preliminary report of a phase II study of folinic acid, 5-fluorouracil, irinotecan (FOLFIRI) plus sunitinib with toxicity, efficacy, pharmacokinetics, biomarker, imaging data in patients with colorectal cancer with liver metastases as 1 st line treatment. Int J Clin Pharmacol Ther 49:96-98

47. Yoshino T, Yamazaki K, Hamaguchi T, Shimada Y, Kato K, Yasui $H$, Boku N, Lechuga MJ, Hirohashi T, Shibata A, Hashigaki S, Li Y, Ohtsu A (2012) Phase I study of sunitinib plus modified FOLFOX6 in Japanese patients with treatment-naïve colorectal cancer. Anticancer Res 32:973-979 
48. Sun W, Powell M, O’Dwyer PJ, Catalano P, Ansari RH, Benson AB III (2010) Phase II study of sorafenib in combination with docetaxel and cisplatin in the treatment of metastatic or advanced gastric and gastroesophageal junction adenocarcinoma: ECOG 5203. J Clin Oncol 28:2947-2951

49. Schultheis B, Kummer G, Zeth M, Brendel E, Xia C, Kornacker M, Strumberg D (2012) Phase IB study of sorafenib in combination with gemcitabine and cisplatin in patients with refractory solid tumors. Cancer Chemother Pharmacol 69:333-339

50. Scagliotti G, Novello S, von Pawel J, Reck M, Pereira JR, Thomas M, Abrão Miziara JE, Balint B, De Marinis F, Keller A, Arén O, Csollak M, Albert I, Barrios CH, Grossi F, Krzakowski M, Cupit L, Cihon F, Dimatteo S, Hanna N (2010) Phase III study of carboplatin and paclitaxel alone or with sorafenib in advanced non-small-cell lung cancer. J Clin Oncol 28:1835-1842

51. Sharma S, Abhyankar V, Burgess RE, Infante J, Trowbridge RC, Tarazi J, Kim S, Tortorici M, Chen Y, Robles RL (2010) A phase I study of axitinib (AG-013736) in combination with bevacizumab plus chemotherapy or chemotherapy alone in patients with metastatic colorectal cancer and other solid tumors. Ann Oncol 21:297-304

52. Rugo HS, Stopeck AT, Joy AA, Chan S, Verma S, Lluch A, Liau KF, Kim S, Bycott P, Rosbrook B, Bair AH, Soulieres D (2011) Randomized, placebo-controlled, double-blind, phase II study of axitinib plus docetaxel versus docetaxel plus placebo in patients with metastatic breast cancer. J Clin Oncol 29:24592465 